Indexed by

\title{
SHEAR BEHAVIOR OF REINFORCED CONCRETE BEAMS STRENGTHENED BY CFRP STRIPS
}

\author{
Lubna Mohammed Abd \\ Mustansiriyah University, \\ College of Engineering, \\ Environmental Engineering \\ Department, \\ Baghdad, Iraq
}

$\mathrm{R} \partial \mathrm{AD} \equiv$

KOBSON

Key words: shear failure, CFRP strips, reinforced concrete beams, epoxy

\section{Cite article:}

Lubna, M. A. [2021]. Shear behavior of reinforced concrete beams strengthened by cfrp strips. Journal of Applied Engineering Science, 19(2), 415 - 423. DOI:10.5937/jaes0-29968 
doi:10.5937/jaes0-29968

\section{SHEAR BEHAVIOR OF REINFORCED CONCRETE BEAMS STRENGTHENED BY CFRP STRIPS}

\section{Lubna Mohammed Abd* \\ Mustansiriyah University, College of Engineering, Environmental Engineering Department, Baghdad, Iraq}

In this research, twelve normal reinforced concrete beams are used with dimensions of $110 \times 10 \times 20 \mathrm{~cm}$, the compressive strength for all specimens is $30 \mathrm{MPa}$. Deformed bars $2 \varnothing 12 \mathrm{~mm}$ with $\varnothing 6 \mathrm{~mm}$ were used for longitudinal reinforcement, while for transverse reinforcement deformed bars with $5 \mathrm{~cm}, 10 \mathrm{~cm}$ and $15 \mathrm{~cm}$ spacing were used. The specimens were tied by different shapes of CFRP strips (tied, inclined and X-shaped). All specimens were tested with two points load by a hydraulic machine to determine the modes of failure, maximum load and deflection. Specimens without CFRP strips were also tested and compared with other specimens. Specimens with the X-shaped strips shows $70 \%$ increment in Pu and decrement in maximum deflection of 39\%. The addition of CFRP strips as a tying material helps in improving the strength and bearing strength of concrete.

Key words: shear failure, CFRP strips, reinforced concrete beams, epoxy

\section{INTRODUCTION}

Reinforced Concrete (RC) henceforth is one of the popular materials used in buildings all around the world. Structures like buildings and bridges uses, as their chief construction material, reinforced concrete. Some or parts of such structures are not fulfilling their structural functions because of some defects on the concrete caused by the poor construction practices, corrosion damage, fire damage, accidental damage, or deterioration caused by environmental action. Some reinforced concrete structures need to be improved as the design and construction faults and load increment or damage induced to the structural members by a seismic or other action. In addition, increasing in traffic volume may result in urgent need for bridges improvement. The replacing of deficient structures requires enormous investments and this would not be a desirable option. Therefore, strengthening becomes more suitable way to improve load-carrying capacity of concrete and prolonging their service life. Despite the effectiveness of other techniques that are widely accepted, engineers succeed in developing a new, better and most promising technique. This technique depends on using carbon fiber reinforced polymer (CFRP) which is more beneficial and gained popularity worldwide. FRP is listed as one of the fruitful technique which is currently used by structural engineers as a new and promising material in construction industry [1].

Khalifa and Nanni (2002) [2] state that the shear strength of beams is increased by CFRP composite in the experimental investigations which are conducted on twelve full-scale reinforced concrete where simply supported beams are designed to fail in shear.

Buyukozturk et. al. (2003) [3] report that the failure pattern that raises concerns is the sudden brittle manner where the CFRP plate deboned prior to ultimate failure. Therefore, such failure pattern needs further critical and close examination.
In this study, a comparison of CFRP wrapped beams with the conventional reinforced concrete beam is focused upon.

\section{OBJECT OF THIS RESEARCH}

The following objectives have been established:

1. To investigate the shear behavior and modes of failure in RC beams with shear deficiencies after strengthening with CFRP strips.

2. To study the effect of various CFRP strips width types and crack failure configurations on the shear behavior of the beam.

3. To propose approaches of design that are based on experiments and analytical studies.

\section{RESEARCH SIGNIFICANCE}

\section{Shear failure}

Shear failures of reinforced concrete beams are characterized as brittle and catastrophic because they do not show any impeding failure. Strengthening in flexure results in the shear capacity reduction of the beam. In many countries, it is common to change the type and usage of building from residential to commercial to develop trading zones of urban areas. Buildings like these have to be reinforced and strengthened to supply additional superimposed loads resulted from such a change. In this study the flexural behavior of reinforced concrete beams that are strengthened with outside bonded CFRP wraps has been studied with varying shear span to depth ratio (a/d). It is found that the RC beams wrapped with CFRP at bottom and extended on sides provided with and without ends anchorages, help in improving the structural performance in terms of stiffness, ductility and load carrying capacity [4]. 


\section{Carbon fiber reinforced polymer (CFRP)}

Carbon Fiber Reinforced Polymer (CFRP) materials have become popular materials for reinforced concrete (RC) structures strengthening in flexural and shear. Several advantages of using CFRP are found. Some of these are the externally bonded material over the conventional steel, high strength to weight ratio, outstanding durability in a variety of environment, ease and speed of installation, flexibility in application techniques, electromagnetically neutral, outstanding fatigue property and low thermal conductivity.

CFRP plates or strips can be bonded to the reinforced concrete members' exterior by using wet lay-up procedures with an epoxy resin/adhesive. CFRP strips or plates are either bonded to tension faces of flexural elements for increasing their bending capacity, or bonded to their side faces for increasing the capacity of shear. Existing reinforced concrete (RC) beams Strengthening is required for numerous reasons for example; heavier loads design, and restoration of the capacity due to deterioration or due to erosion design and construction [4]. Carbon fiber reinforced polymer is a widespread technique used for shear strengthening and it has been applied to many structural elements like beams, columns, and slabs etc. This research focuses upon CFRP consisting of flexible strips where carbon fiber reinforced polymer is strong and light fiber reinforced plastic contains carbon fibers. This can be used where ever we require high strength and rigidity. Furthermore, these CFRP strips are bonded by using epoxy adhesive [5].

\section{EXPERIMENTAL PROGRAM}

\section{Materials}

In this study, the performance and structural behavior of the specimens have been checked by using the materials:

\section{A. Cement}

The ordinary Portland cement OPC type I is used for entire work which is from Bazyan, Al-Sulaimaniya, Iraq.

B. Fine aggregates

The river sand particles are used as the fine aggregates with fineness modulus (2.6) and specific gravity 2.63. The fine aggregates has a maximum size less than $(5 \mathrm{~mm})$ and this conforms to the British Standards (BS 882-1992) [6] as shown in Table 1 and Figure 1 below:

Table 1: Grading of fine aggregate

\begin{tabular}{|c|c|c|}
\hline No. & Sieve size $(\mathrm{mm})$ & $\begin{array}{c}\text { Present work fine aggregate } \\
\text { (\% passing) }\end{array}$ \\
\hline 1 & 5.0 & 90.52 \\
\hline 2 & 2.36 & 80.10 \\
\hline 3 & 1.180 & 67.72 \\
\hline 4 & 0.60 & 44.64 \\
\hline 5 & 0.30 & 7.09 \\
\hline 6 & 0.15 & 3.43 \\
\hline
\end{tabular}

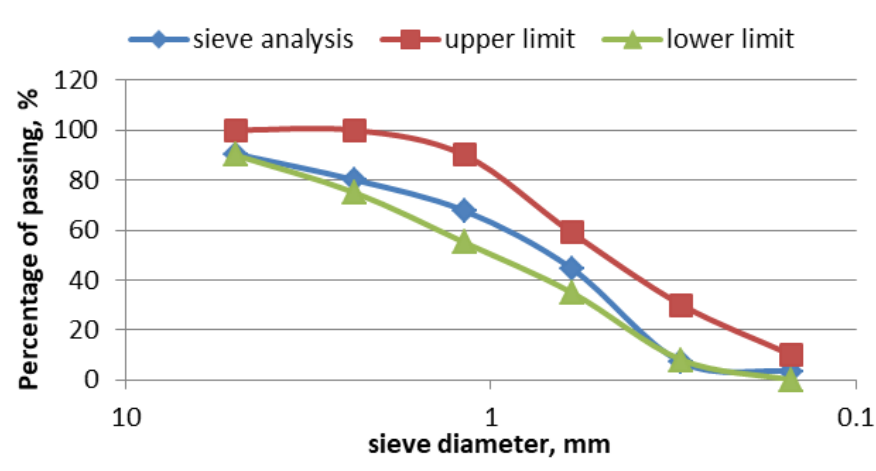

Figure 1: Grading of fine aggregate

Table 2: Grading of coarse aggregate

\begin{tabular}{|c|c|c|}
\hline No. & Sieve Size $(\mathrm{mm})$ & $\begin{array}{c}\text { Present Work of Coarse } \\
\text { Aggregate (\% Passing) }\end{array}$ \\
\hline 1 & 20 & 100 \\
\hline 2 & 14 & 100 \\
\hline 3 & 10 & 74.5 \\
\hline 4 & 5.0 & 1.23 \\
\hline 5 & 2.36 & 0 \\
\hline
\end{tabular}

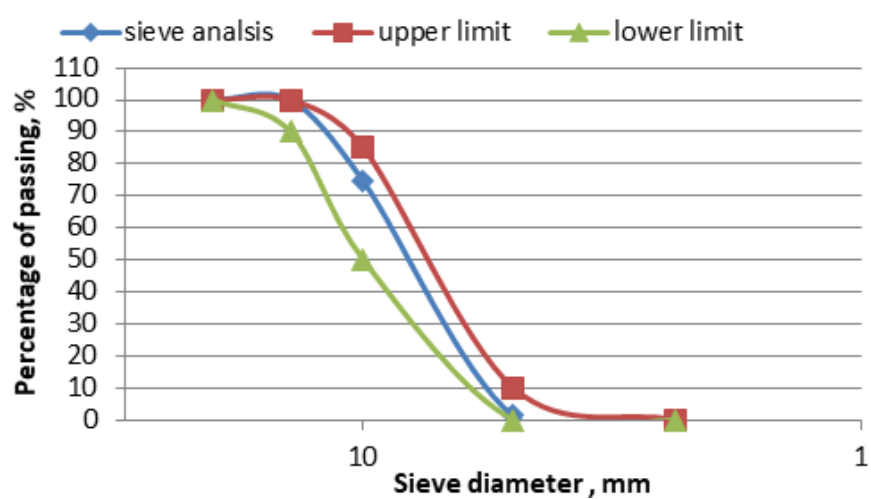

Figure 2: Grading of coarse aggregate

\section{Coarse Aggregates}

The coarse aggregates with maximum size $(20 \mathrm{~mm})$ and specific gravity 2.62 are used. The ideal coarse aggregate should be clean and $100 \%$ crushed aggregate with a minimum of flat and elongated particles is used. Coarse aggregate is brought from natural source. Table 2 and Figure 2 show the grading of the coarse aggregate, which conforms to the British Standards (BS 8821992) [6].

\section{Carbon Fiber Reinforced Polymer (CFRP)}

It is a very strong, light fiber reinforced plastic which contains carbon fibers. It can be used whenever high strength and rigidity are desired. Carbon fiber reinforced polymer is a popular a type of shear strengthening technique that has been applied to many concrete structural elements like beams, columns, and slabs etc.,

\section{E. Epoxy resin}

Epoxy is a hardening agent which works to cure it into the very strong adhesive. CFRP strips are bonded by 
using epoxy adhesive. Figure 3 below shows the type of epoxy named Sikadur 530 that is used in the study. The mix proportion of Epoxy resin (1:4) and time of lefting the Epoxy resin to dry on the specimen is 7 days according to the manufacturer.

\section{F. Steel Reinforcement}

In this study the longitudinal steel is deformed bars $2 \varnothing 12 \mathrm{~mm}$ for tension stresses and $2 \varnothing 4 \mathrm{~mm}$ for compression stresses and for bonding with transverse reinforcement which is deformed bars $\varnothing 6 \mathrm{~mm}$ for different spacing $5 \mathrm{~cm}, 10 \mathrm{~cm}$ and $15 \mathrm{~cm}$ as shown in Figure 4 below:

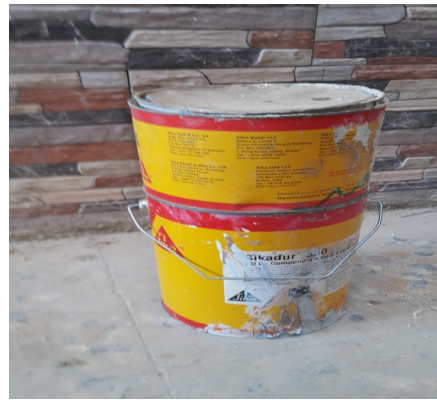

Figure 3: Epoxy used in the work

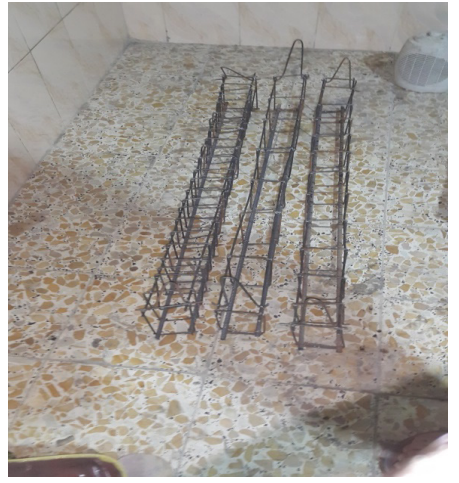

Figure 4: Steel reinforcement

\section{DESIGN}

Normal concrete beams of $\left(110^{*} 10^{*} 20\right) \mathrm{cm}$ has been made using confident proportions of cement, fine aggregate, coarse aggregate and water. In the program of testing, the compressive strength of concrete is kept constant which it is $30 \mathrm{MPa}$. The mix proportion is $(1: 2: 3)$ by weight for cement, sand and gravel respectively with $\mathrm{w} / \mathrm{c}$ ratio of $(0.35)$. All specimens are casted in wooded mold as shown in Figure 5 and totally vibrated on a vibrating table to reduce the air content. The vibration time to reach full compaction is certain upon by the end of air bubbles passage from concrete fresh state. The specimens are then cast into three layers, in which 25-30 seconds are required for compaction per layer and left for curing for about 28 days.

The beam is tested by a hydraulic universal machine of (3000 kN) capacity. This machine compressed the beam by two points load as shown in Figure 6.

The beams are classified into four groups according to the shape of CFRP strips as it will explain later in Table 3 then wrapping with CFRP strips of $5 \mathrm{~cm}$ width of strips

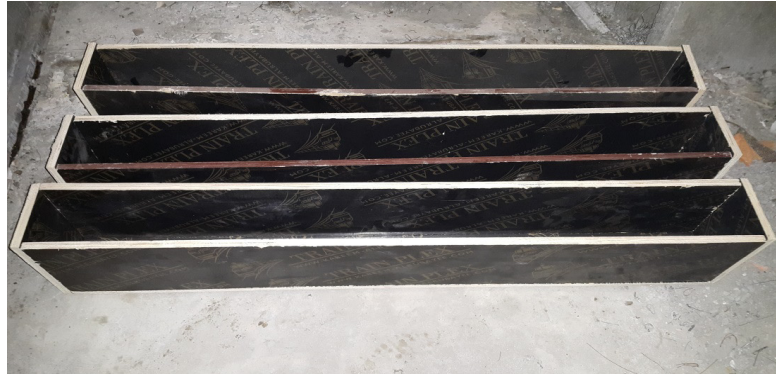

Figure 5: Mold of the study

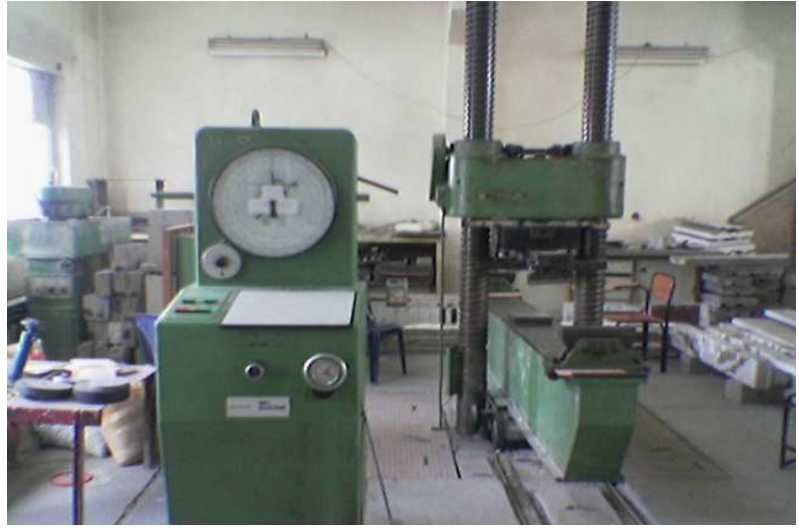

Figure 6: Hydraulic machine

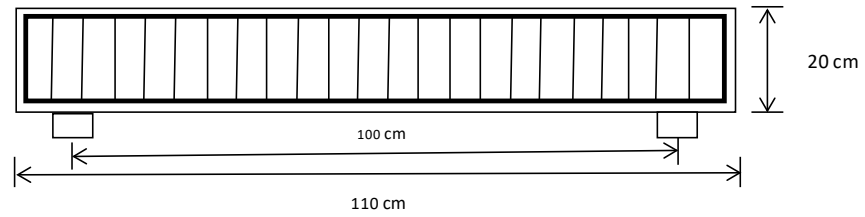

Figure 7: Profile of beam specimens

with $10 \mathrm{~cm}$ spacing between strips as shown in Figure 7. After that, the specimens left for 7 days for adhesion with epoxy according to the manufacturer.

\section{TEST RESULTS}

As mentioned before, the main aim of this research is to study the shear behavior of 12 beams are designed with various shapes of CFRP strips such as ( ties, inclined and $\mathrm{X}$ - shape) and compared them with the reference beam which does not have CFRP strips as shown below:

\section{Ultimate loads and cracking loads}

The ultimate load is the maximum load of the member which reaches to failure, while Cracking load is defined as the load which is the first visible surface cracks on the surfaces of the member. Table 4 and Figures (8-11) show the values of these loads.

From Table 4 the Ultimate loads is increased when the beam strips worked with CFRP strips for the same spacing between ties reinforcement with average increment percentage of $51 \%, 70 \%$ and $87 \%$ for ties, inclined and the X-shaped strips respectively because the higher bond strength of the CFRP strips especially in the case 
of X-shaped strips technique. Also, the average increment of $\mathrm{Pu}$ is $14 \%$, and $11 \%$ for decreasing the spacing between ties reinforcement by $5 \mathrm{~cm}$. the Figures (8-11) shows these results.

\section{Load-Deflection Curves}

The load-deflection curves in this work are taken at center of all the tested beams. Table 5 below illustrates the

Table 3: Name of beam specimens with description

\begin{tabular}{|c|c|}
\hline Beam name & Description \\
\hline $15 \mathrm{~cm}$-without CFRP & Beam without CFRP strips and $15 \mathrm{~cm}$ spacing between transverse reinforcement \\
(ties reinforcement)
\end{tabular}

Table 4: Ultimate and cracking loads

\begin{tabular}{|c|c|c|c|}
\hline Beam name & $\begin{array}{l}\mathrm{Pu} \\
(\mathrm{kN})\end{array}$ & $\begin{array}{l}\mathrm{Pcr} \\
(\mathrm{kN})\end{array}$ & $\begin{array}{c}\mathrm{Pcr} / \mathrm{Pu} \\
(\%)\end{array}$ \\
\hline $15 \mathrm{~cm}$-without CFRP & 50 & 12.5 & 25 \\
\hline 10cm-without CFRP & 60.5 & 14 & 23 \\
\hline $5 \mathrm{~cm}$-without CFRP & 69 & 15 & 22 \\
\hline 15cm-Ties CFRP & 80 & 15 & 20 \\
\hline 10cm-Ties CFRP & 90.5 & 16 & 18 \\
\hline 5cm-Ties CFRP & 99.5 & 17.5 & 18 \\
\hline 15cm-Inclined CFRP & 92 & 15.5 & 17 \\
\hline 10cm-Inclined CFRP & 100 & 17.5 & 18 \\
\hline 5cm-Inclined CFRP & 110 & 18 & 16 \\
\hline 15cm-X- shaped CFRP & 100 & 17.5 & 18 \\
\hline 10cm-X-shaped CFRP & 111.5 & 20 & 18 \\
\hline 5cm-X-shaped CFRP & 122 & 22.5 & 18 \\
\hline
\end{tabular}

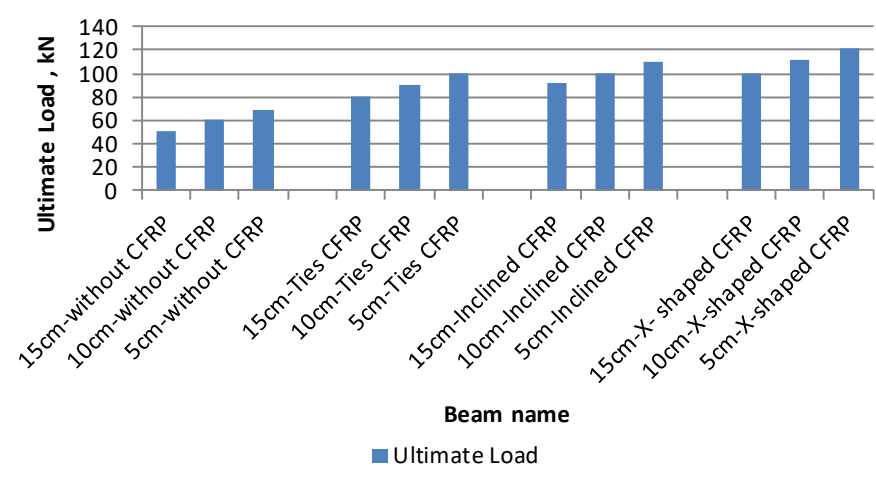

Figure 8: Ultimate loads values

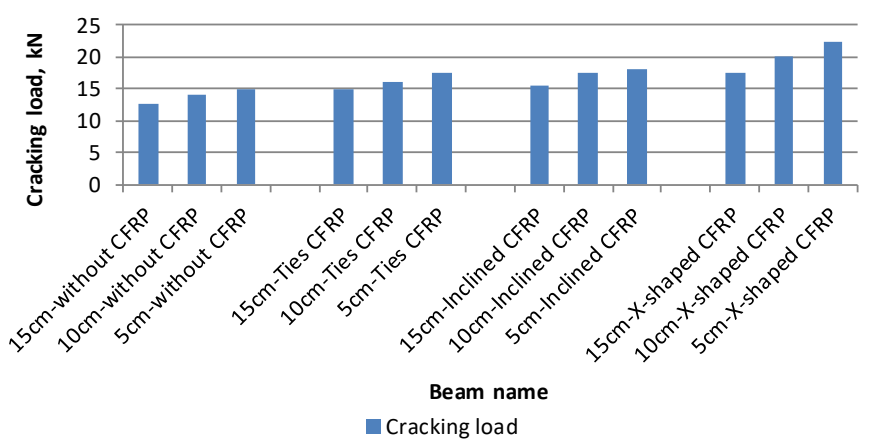

Figure 9: Cracking loads values

Istraživanja i projektovanja za privredu ISSN 1451-4117 Journal of Applied Engineering Science Vol. 19, No. 2, 2021 

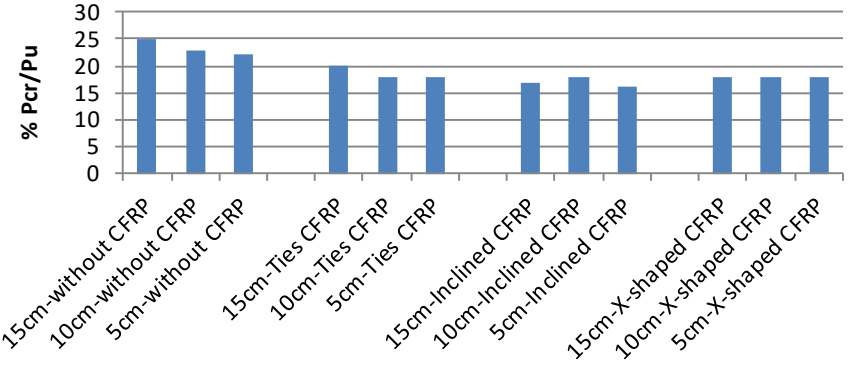

Beam name

$\mathrm{Pcr} / \mathrm{Pu} \%$

Figure 10: The percentages of Pcr/Pu \%

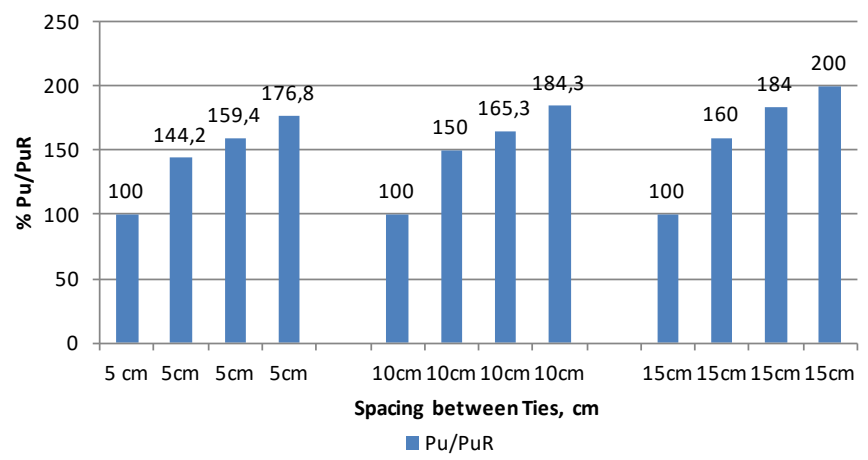

Figure 11: The percentage Pu/PuR

maximum deflection in center of beams with maximum load, and Figures from (12-14) show the load-deflection curves of specimens.

As shown in Table 5, the average decrement of maximum deflection for specimens was $14 \%, 22 \%$ and $39 \%$ for ties, inclined and the X-shaped strips respectively. Also, the average decrement of maximum deflection is $10 \%$ and $8 \%$ for decreasing the spacing between ties reinforcement by $5 \mathrm{~cm}$. The Figures from 12 to 14 show the maximum deflection values.

Table 5: Ultimate loads and maximum cracks

\begin{tabular}{|c|c|c|}
\hline Beam name & $\begin{array}{c}\mathrm{Pu} \\
(\mathrm{kN})\end{array}$ & $\begin{array}{c}\text { Maximum Deflection } \\
(\mathrm{mm})\end{array}$ \\
\hline 15cm-without CFRP & 50 & 8.5 \\
\hline 10cm-without CFRP & 60.5 & 7.8 \\
\hline $5 \mathrm{~cm}$-without CFRP & 69 & 7.1 \\
\hline & & \\
\hline $15 \mathrm{~cm}$-Ties CFRP & 80 & 7 \\
\hline $10 \mathrm{~cm}$-Ties CFRP & 90.5 & 6.9 \\
\hline $5 \mathrm{~cm}$-Ties CFRP & 99.5 & 6.33 \\
\hline & & \\
\hline $15 \mathrm{~cm}$-Inclined CFRP & 92 & 6.3 \\
\hline $10 \mathrm{~cm}$-Inclined CFRP & 100 & 6.1 \\
\hline $5 \mathrm{~cm}$-Inclined CFRP & 110 & 5.9 \\
\hline & & \\
\hline 15cm-X- shaped CFRP & 100 & 5.5 \\
\hline $10 \mathrm{~cm}$-X-shaped CFRP & 111.5 & 4.7 \\
\hline $5 \mathrm{~cm}-X$-shaped CFRP & 122 & 4.22 \\
\hline
\end{tabular}

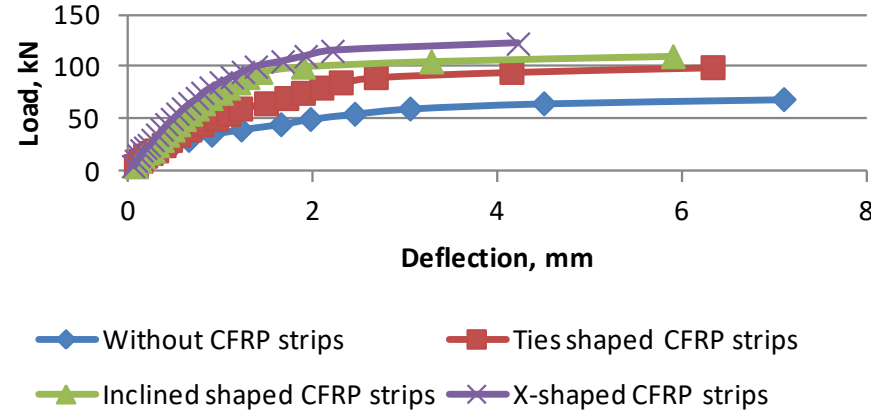

Figure 12: Load-deflection curves for $5 \mathrm{~cm}$ spacing between ties reinforcement

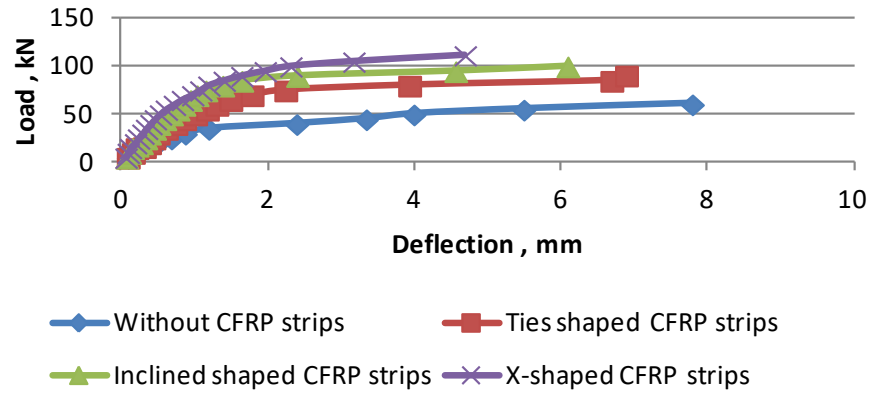

Figure 13: Load-deflection curves for $10 \mathrm{~cm}$ spacing between ties reinforcement

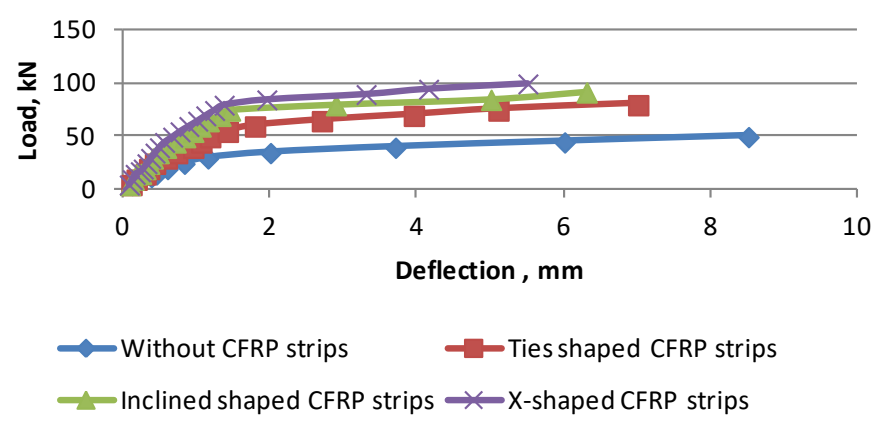

Figure 14: Load-deflection curves for $15 \mathrm{~cm}$ spacing between ties reinforcement

\section{Crack patterns and modes of failure}

There are two modes of failure the first one is flexural failure, this failure mode occurs when the loads on the beam exceed its flexural capacity. The shear strength of the beam should be greater than its flexural strength otherwise the shear failure would occur before flexural failure.

The second one is the shear failure, this failure occurs when the beam has shear resistance lower than flexural strength and the shear force exceeds the shear capacity of different materials of the beam. This type of failure is sudden and provides no warning i.e. brittle failure. This mode of failure is common in beams with low or no web reinforcement.

Beams, examined here, are designed with deformed bars of $\Phi 5 @(5,10$ and 15) cm spacing as ties reinforcement. These beams fail by punching or flexure according to the reinforcement and the applied load. Steel reinforcement 
tied well together to ensure that no bond failure between steel bars and surrounding concrete can take place. Table 6 and Figure 15 show the maximum cracks for each beam. Also, Figures (16-19) show the modes of failure for each beam.

From the Figures above, the all three beams without wrapping CFRP strips performed modes of diagonal shear failure only, and the width of cracks of beam failure which has $15 \mathrm{~cm}$ spacing is bigger and clearly shown than 10 and $5 \mathrm{~cm}$.

When the beams are wrapped with ties CFRP strips, the failure varies according to the spacing between transverse reinforcement as shown in Figures. In $15 \mathrm{~cm}$ spacing, the failure is diagonal shear with appeared small cracks of flexural failure.

While the spacing is $10 \mathrm{~cm}$, the beam tends to fail shear and flexural but with thinner width cracks.

Finally in $5 \mathrm{~cm}$ spacing between ties reinforcement, the beam shows better performance of failure with diagonal shear failure only with very thin crack width.

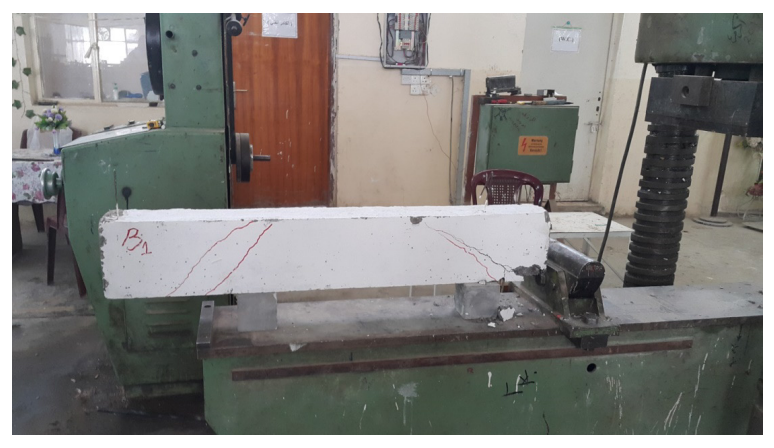

(a) $15 \mathrm{~cm}$

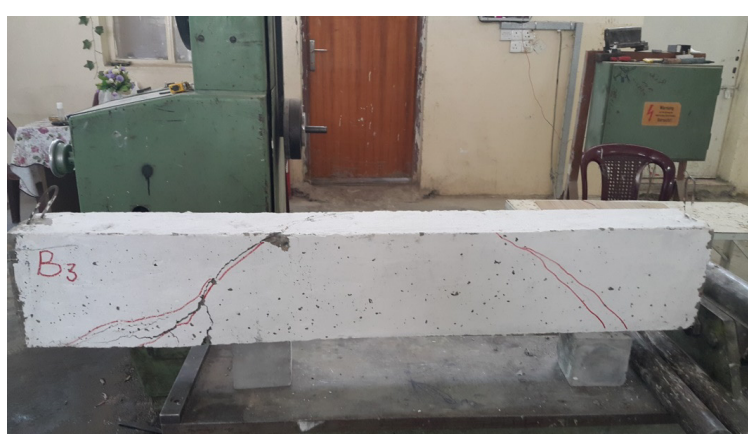

(b) $10 \mathrm{~cm}$

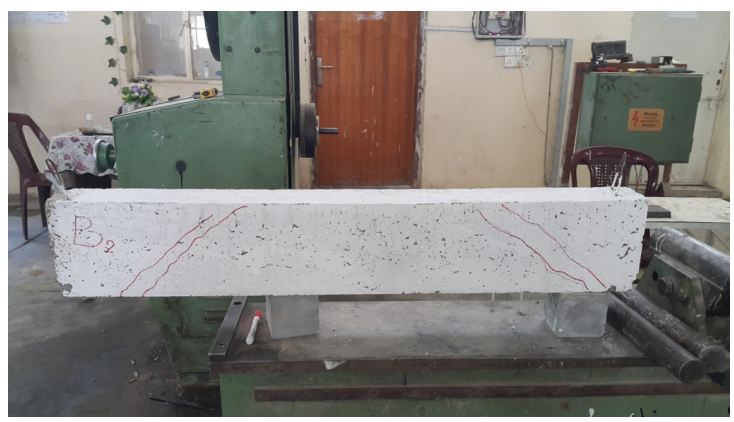

(c) $5 \mathrm{~cm}$

Figure 16: Modes of failure of specimens without CFRP strips

Table 6: Ultimate loads and maximum cracks

\begin{tabular}{|c|c|c|c|}
\hline Beam name & Pu $(\mathrm{kN})$ & Maximum Deflection $(\mathrm{mm})$ & Modes of failure \\
\hline $15 \mathrm{~cm}$-without CFRP & 50 & 8.5 & Shear failure \\
\hline $10 \mathrm{~cm}$-without CFRP & 60.5 & 7.8 & Shear failure \\
\hline $5 \mathrm{~cm}$-without CFRP & 69 & 7.1 & Shear failure \\
\hline & & & Shear failure and Flexural failure \\
\hline $15 \mathrm{~cm}$-Ties CFRP & 80 & 7 & Shear failure and Flexural failure \\
\hline $10 \mathrm{~cm}$-Ties CFRP & 90.5 & 6.9 & Shear failure \\
\hline $5 \mathrm{~cm}$-Ties CFRP & 99.5 & 6.33 & Shear failure \\
\hline & & & Shear failure and Flexural failure \\
\hline $15 \mathrm{~cm}$-Inclined CFRP & 92 & 6.3 & Flexural failure \\
\hline $10 \mathrm{~cm}$-Inclined CFRP & 100 & 6.1 & \\
\hline $5 \mathrm{~cm}$-Inclined CFRP & 110 & 5.9 & Shear failure \\
\hline & & & Flexural failure \\
\hline $15 \mathrm{~cm}$-X- shaped CFRP & 100 & 5.5 & Flexural failure \\
\hline $10 \mathrm{~cm}$-X-shaped CFRP & 111.5 & 4.7 & 4.22 \\
\hline $5 \mathrm{~cm}$-X-shaped CFRP & 122 & &
\end{tabular}




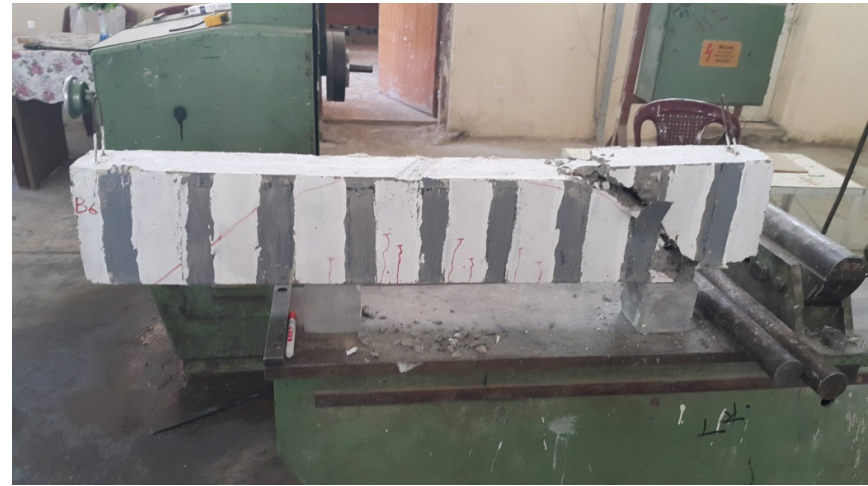

(a) $15 \mathrm{~cm}$

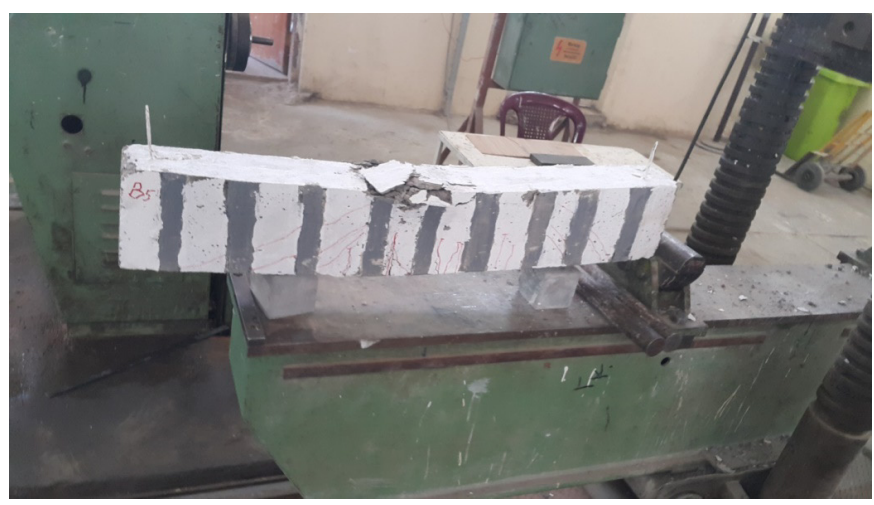

(b) $10 \mathrm{~cm}$

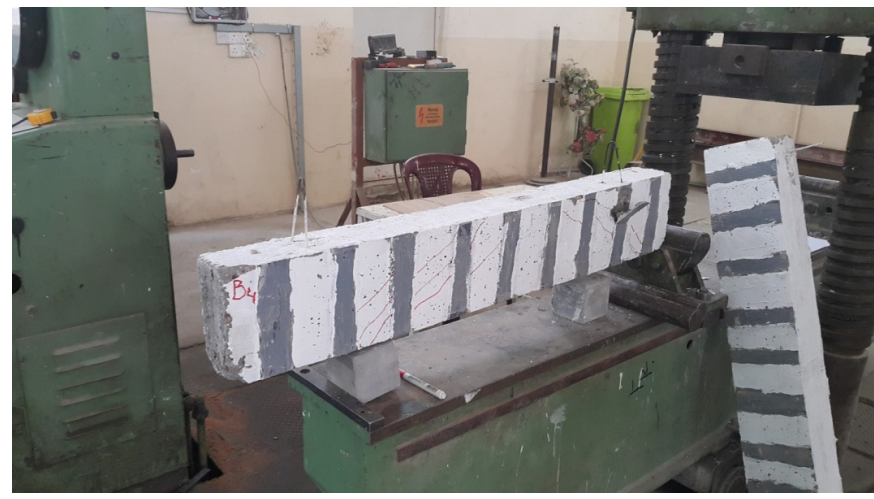

(c) $5 \mathrm{~cm}$

Figure 17: Modes of failure of specimens with ties CFRP strips

When the beam wrapped with inclined CFRP strips, as shown in figures above, the beam tends to control the cracks generally with shear failure only especially at 15 $\mathrm{cm}$ and $10 \mathrm{~cm}$ spacing.

While the beam with $5 \mathrm{~cm}$ spacing, the failure is flexural only and the beam control the shear failure so, it is better than the beams with $10 \mathrm{~cm}$ and $15 \mathrm{~cm}$ spacing between ties reinforcement.

As a result, the beams with inclined wrapped CFRP strips tend to show performance of failure better than tied strips because they are tied against the shear failure.

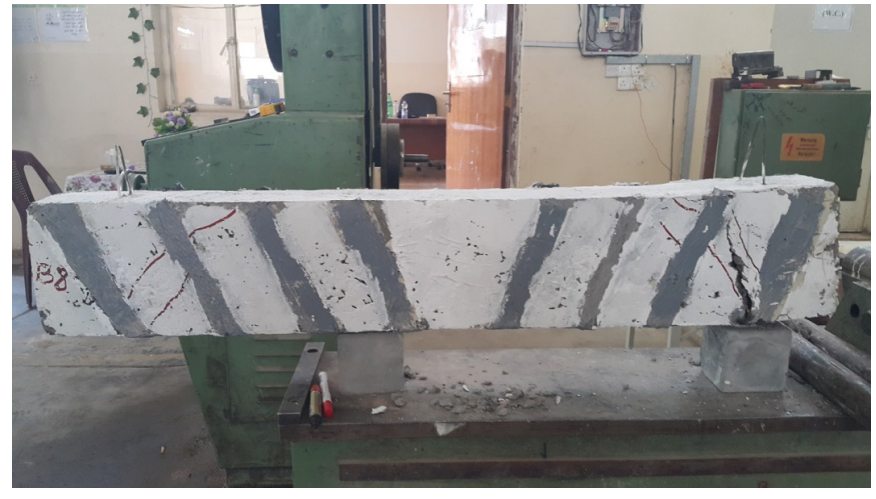

(a) $15 \mathrm{~cm}$

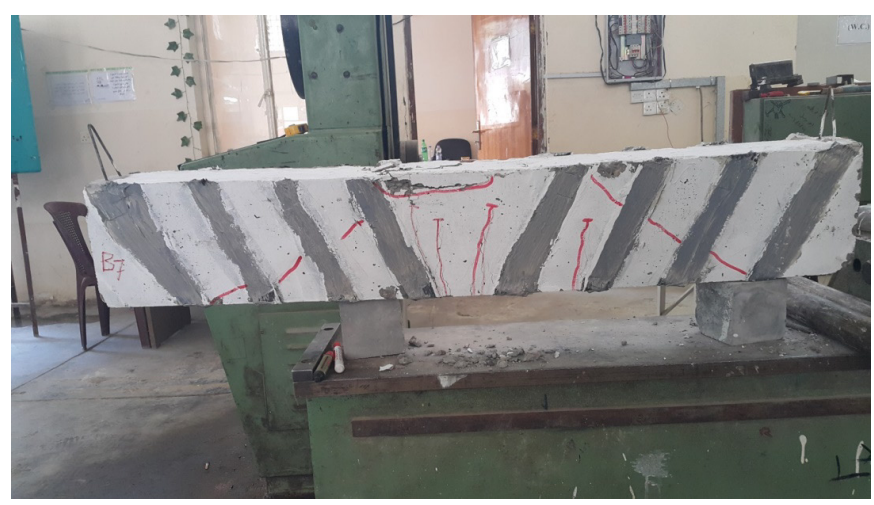

(b) $10 \mathrm{~cm}$

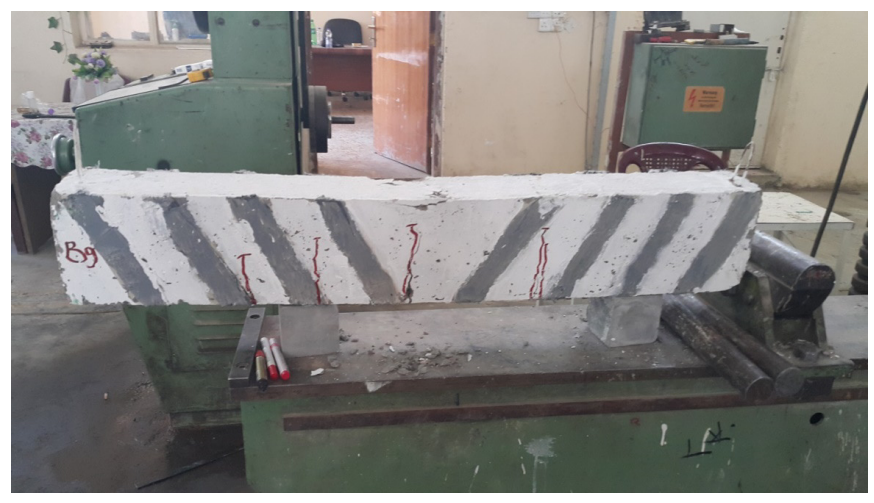

(c) $5 \mathrm{~cm}$

Figure 18: Modes of failure of specimens with inclined CFRP strips

The Figures above show that the excellent behavior of beam against failure is the X-shaped CFRP wrapping, it could control the patterns and crack width of shear and flexural failure for the beams to minimum. The beam has the higher values of strength and the failure is only at edges with very thin crack width as the spacing between transverse reinforcement decreased.

\section{CONCLUSION}

Based on the experimental results of all 12 beams subjected to two-point loads, the following conclusions are 


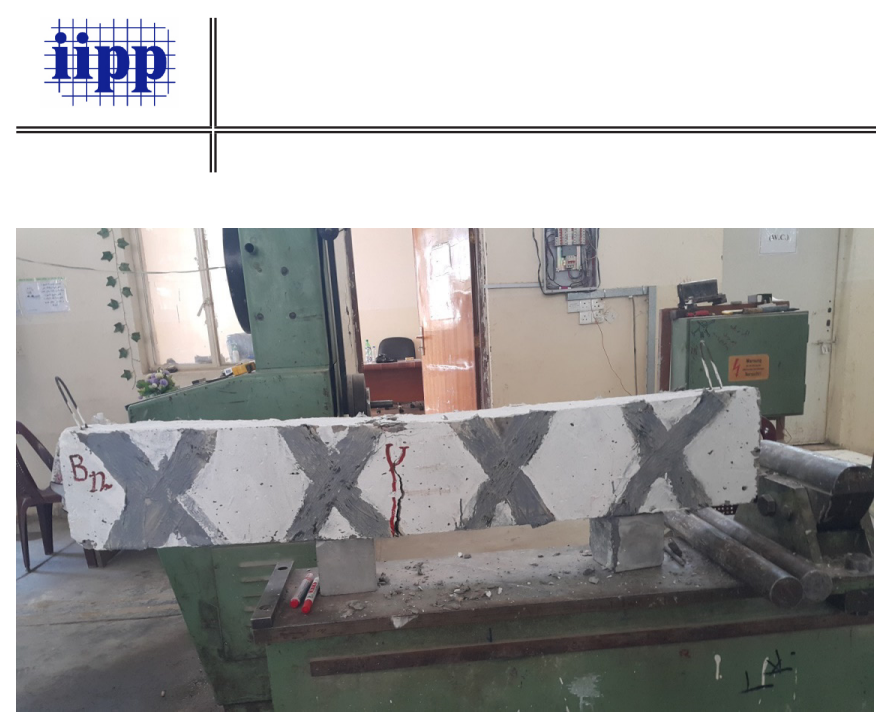

(a) $15 \mathrm{~cm}$

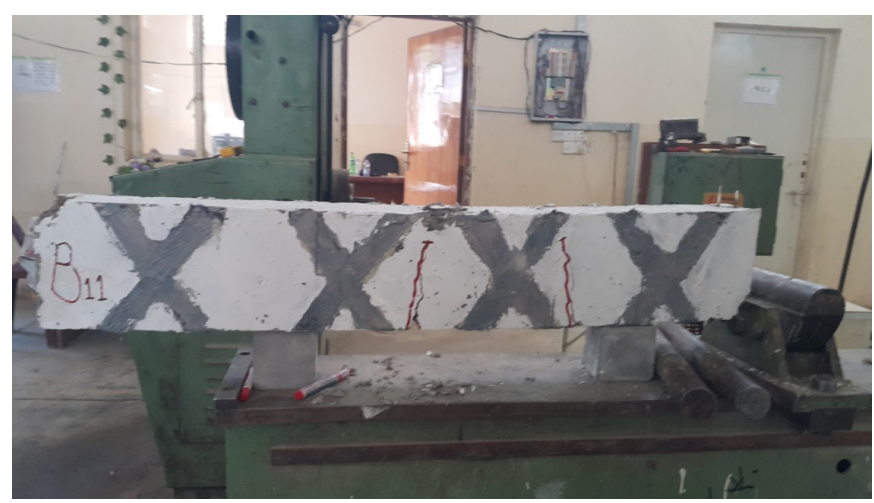

(b) $10 \mathrm{~cm}$

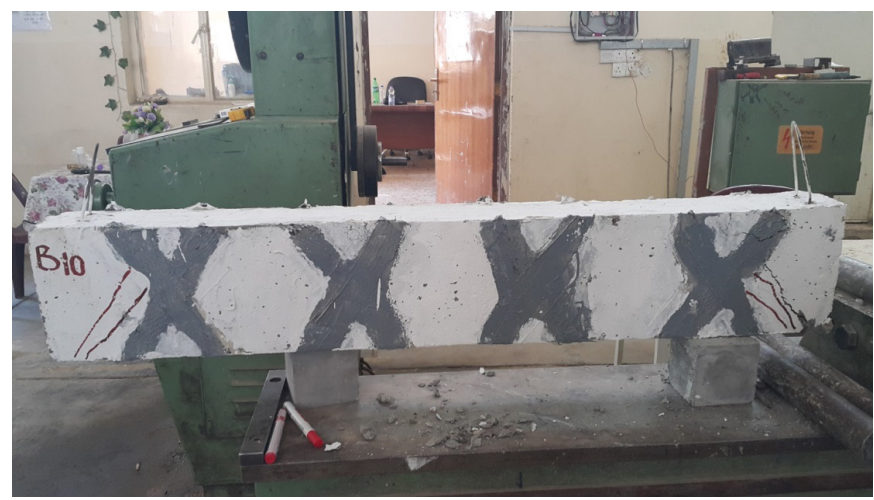

(c) $5 \mathrm{~cm}$

Figure 19: Modes of failure of specimens with X-shaped CFRP strips

reached out according to the effect of wrapping beams with CFRP strips and by changing the spacing between ties reinforcement:

1. The load carrying capacity of the CFRP strips wrapped beams is higher than the conventional beams. While the maximum deflection is lesser than the conventional beams.

2. Crack width and failure of the inclined and X- shaped CFRP strips is controlled and thinner than the ties shaped CFRP strips and conventional beams.

3. The inclined and X- shaped CFRP strips increase the ultimate loads and strength of beams especially the X-shaped strips and decrease the failure to low values. Also, the magnitude of the increase ultimate load and decrease maximum deflection and modes of failure are related to the shape of CFRP strips wrapped to the beam.

4. The results show that CFRP strips may be used to increase the strength against the load divergence and stiffness of beams without causing brittle failure associated with this strengthening technique.

5. The use of CFRP strips with different shapes opened from the top represents the indeed performed beams and this technique could decrease the cost. CFRP strips show better performance to weather by coating the strip region by epoxy and this layer could increase the concrete strength against weather.

6. From the above points, it could be concluded and recommended to use CFRP strips especially the Xshaped because they show better performance than the conventional beams and improve shear capacity of the beam against failure. As well as, they provide a solution for extending the service life of concrete structure.

\section{RECOMMENDATIONS}

1. To increase the strength of reinforced concrete and conserve the concrete bearing against loads it is recommended to use the CFRP strips especially the Xshaped one as explained in this research.

2. It can be used and performed in many projects which is big projects for example, but not limited Silo grain storage because it causes cracks in long term to avoid these problems.

3. It can be performed and removed easily.

4. It can change the modes of failure and decreased it.

5. It can withstand weather conditions such as heat and humidity and sulfate attack by coating the strips with light layer of Epoxy.

\section{ACKNOWLEDGEMENT}

I would like to thank Mustansiriyah University-College of Engineering for facilitating the practical part of this research.

\section{REFERENCES}

1. Jumaat, M. Z., Rahman, M. M., \& Alam, M. A. (2010). Flexural strengthening of RC continuous $T$ beam using CFRP laminate: A review. International Journal of the Physical Sciences, 5(6), (pp. 619-625).

2. Khalifa, A., \& Nanni, A. (2002). Rehabilitation of rectangular simply supported RC beams with shear deficiencies using CFRP composites. Construction and Building Materials, 16(3), (pp. 135-146).

3. Bukhari, I. A., Vollum, R. L., Ahmad, S., \& Sagaseta, J. (2010). Shear strengthening of reinforced concrete beams with CFRP. Magazine of Concrete Research, 62(1), (pp. 65-77). 
4. Asad ur Rehman Khan, Shamsoon Fareed, (2014). Behaviour of Reinforced Concrete Beams Strengthened by CFRP Wraps with and without End Anchorages. Fourth International Symposium on Infrastructure Engineering in Developing Countries, IEDC. Procedia Engineering 77 ( 2014 ) 123 - 130.

5. B. Srudhira, M. Anil kumar, K. J. Brahma Chari, (2019). Evaluation of Shear Behaviour of RC Beams Using CFRP. International Journal of Recent Technology and Engineering (IJRTE) ISSN: 2277-3878, Volume-7, Issue-6C2, April 2019.
6. BS882. 1992. "specification for aggregate from nurture source for concrete."(December 1992). 